\title{
Organic-Free Au-Pd Alloys on Germanium Substrate via Spontaneous Galvanic Displacement Reaction
}

\author{
Kang Yeol Lee, Sang Woo Han, ${ }^{;-}$and Hee Cheul Choi" \\ Department of Chemistry and Division of Advanced Materials Science, \\ Pohang Lniversity of Science and Technology (POSTECH), Pohang 790-784, Korea. ${ }^{*}$-mail: choihcapostechedu \\ ${ }^{\dagger}$ Department of Chemistry and KI for the NanoCentury, KAIST, Daejeon 305-701, Korea. "E-mail: sangu'oohanakast ac kr \\ Received September 1, 2009, Accepted October 20, 2009.
}

Key Words: Organic-free. Galvanic displacement, Au-Pd Alloys. Co-deposition

The unique electrical and optical properties of semiconductor and metal nanocrystals have been attracted for their potential applications in nanoelectronics. optoelectronics. catalysis. and biomedical imaging/therapeutics. ${ }^{.7}$ Since these properties are dramatically affected by the sizes and geometrical shapes of nanocrystals, various chemical synthetic strategies have been developed to precisely control the aforementioned factors. A representative approach to șynthesize semiconductor or metal nanocrystals employs the reaction of precursors in solution phase at elevated temperature in the presence of organic stabilizing agents which prohibit severe aggregation of the produced nanocry stals ${ }^{1.3}$ Although this traditional synthetic method has successfully produced various nanocrystals having very narrow size distributions, the presence of organic molecules on their surfaces frequently causes problems as a significant barrier for example. in electron and photon transports.

Recently a facile chemical approach enabling spontaneous formations of metal nanocrystals on solid substrates in the absence of organic stabilizing agent has been developed. ${ }^{8.13}$ The galvanic displacement. a mechanism-based nomenclature for the spontaneous metal nanocrystal formation, involyes direct electron transfer from metal or semiconductor substrates (electron donors) to metallic precursor cations (electron acceptors) at room temperature according to their relative electrochemical redox potentials. A representative example of metal nanocry stals synthesized by the galvanic displacement is $\mathrm{Au}$ nanoparticles on germanium (Ge) surface. ${ }^{8}$ In this case. the electrons spontaneously donated by Ge fully reduce $\mathrm{Au}^{3-}$ ions into Au nanocrystals when both species are simply brought into contacts in aqueous solution. To take the best advantage of its simplicity. the galvanic displacement process has been mostly applied to sytnthesize monometallic noble metal nanocrystals such as $\mathrm{Au}, \mathrm{Ag}$. Pd, Pt, and etc. ${ }^{8-13}$ on $\mathrm{Ge}$ or other semiconductors such as GaAs. InP substrate of which cations generally have significantly large positive standard reduction potential values. On the contrary there is not much report about the formation of composite alloys which are of great interest from scientific and technological perspectives owing to their composition-dependent optical catalytic. electronic and magnetic properties. ${ }^{l+}$

Herein we introduce the spontaneous formation of All-Pd alloys via galvanic displacement process. which is the first demonstration of organic-free bimetallic alloy crystals to the best of our knowledge. The galvanic displacement derived direct formation of Au-Pd bintetallic nanostructures on $\mathrm{Ge}$ substrate is confirmed by using scanning electron microscopy (SEM), transmission electron microscopy (TEM), energy-dispersive X-ray spectroscopy (EDS), X-ray diffraction (XRD). and surface-enlanced Raman scattering (SERS). The organicfree Au-Pd alloy's are anticipated to exhibit high catalytic activities on the conventionally applied reactions such as synthesis of hydrogen peroxide. hydrodesulfuriztion of thiophene derivatives. hydrogenation of aromatics. ${ }^{16.17}$ and oxidation of alcohols to aldehydes. ${ }^{18}$

\section{Experimental}

Chemicals. $\mathrm{HAuCl}_{4}(99.9+\%)$ and $\mathrm{Na}_{2} \mathrm{PdCl}_{4}(99.998 \%)$ were used as purchased from Aldrich. Other chenucals, unless specified. were reagent grade, and deinoized water $(\mathrm{R}>18.0 \mathrm{M} \Omega$ ) was used when preparing aqueous solutions. Ge wafers (Gadoped p-type $\mathrm{Ge}(100)$, resistivity: $0.005-0.1 \Omega \cdot \mathrm{cm})$ were used as a substrate.

Preparation of Au-Pd alloy films. In a typical synthesis of Au-Pd bimetallic thin films. $100 \mu \mathrm{L}$ of premixed aqueous solution of $\mathrm{HAuCl}_{4}$ (concentration of stock solution: $5 \mathrm{mM}$ ) and $\mathrm{Na}_{2} \mathrm{PdCl}_{4}$ (concentration of stock solution: $5 \mathrm{mM}$ ) was added into $900 \mu \mathrm{L}$ of deionized water to make the final $1 \mathrm{mM}$ solution. To this solution. a piece of Ge wafer substrate precleaned with isopropanol and dried under $\mathrm{N}_{2}$ flow was immersed. After $12 \mathrm{hr}$. the Ge substrate containing Au-Pd bimetallic alloy films was thoroughly rinsed with deionized water to remove unreacted precursors. then dried under ambient conditions.

Characterization of Au-Pd alloy thin films. TEM images were obtained using a Philips CM 200 transmission electron microscope operating at $200 \mathrm{kV}$. High-resolution TEM (HRTEM) and scanning TEM (STEM) images were acquired using a JEOL JEM-2100F (200 kV) transnission electron microscope equipped with a field enussion gun and an ultra-highresolution observation system. This instnument includes a scanning intage device to operate as STEM from TEM in a serial manner. It also possesses several atom level probes connected to Oxford INCA X-ray energy dispersive spectrometer and Gatan 2D digital-parallel acquisition software. The electron probe size and dwell time used in the STEM-EDS mapping experiments were $0.1 \mathrm{~nm}$ and $0.2 \mathrm{nts}$ per pixel, respectively. 
The SFM and Tए,SS data of the samples were taken with a field emission scanning clectron microscope (FГSF, Phillips Model XL 30 S FEG). The XRD patterns werc obtained using a Bruker AXS D8 DISCOVГR ditlractometer with a Cu $K_{a}$ $(1.5406 \AA$ ) radiation. For STRS measurements, Gic substrates containing $\mathrm{Au}, \mathrm{Pd}$, and Au-Pd bimetallic films were soaked in $1 \mathrm{mM}$ 1,4-phenv lenediisoevanide (1,4-PDI) in ethanol solution ovemight, then washed with ethancl and dried under ambient conditions. Raman spectra were obtained using a Jobin Ywon/ IIORIB $\triangle \mathrm{I}$ abR $\Lambda \mathrm{M}$ spectroncter with $632.8 \mathrm{~nm}$ line of an aircosled I Ie/ Ne laser as an excitation sourec

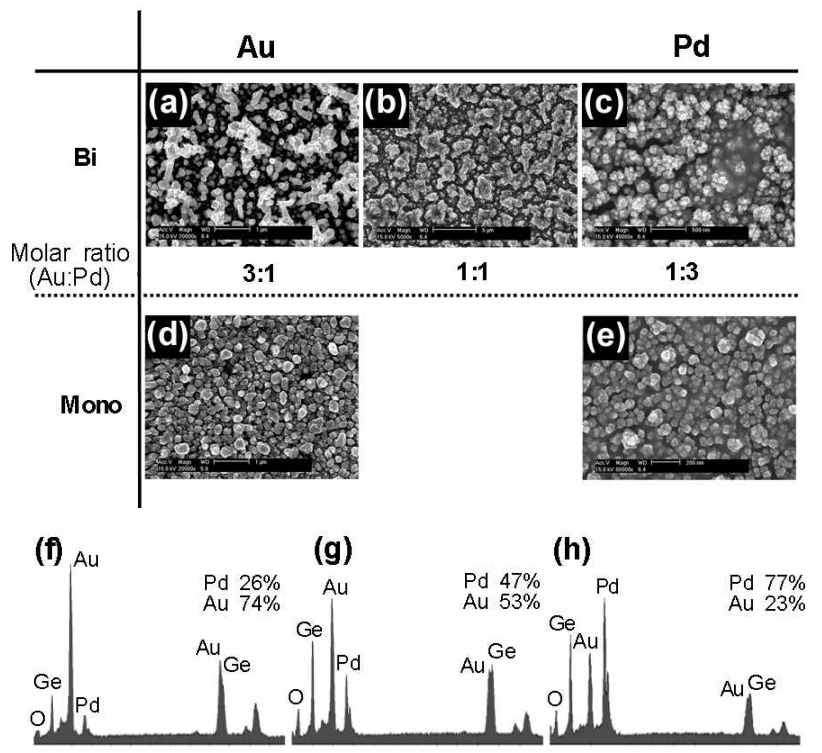

Figure 1. SLM images of bimetallic (a) Au-Pd (3:1). (b) Au-Pd (1:1). (c) Au-Pd (1:3), and monometallic (d) Au, (e) Pd nanocrsstal lilms formed via spontancous galvanic displacement process on Gic substrates. LDS spectra of (t) $\Lambda u-P d(3: 1)$. (o) $\Lambda u-P d(1: 1)$. and (1) $\Lambda u-P d$ (1:3) jilms on (je subsirales (a)

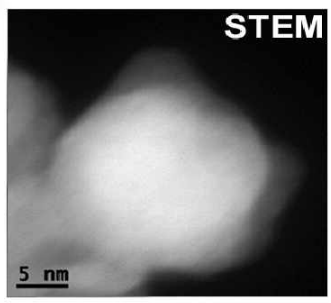

(c)

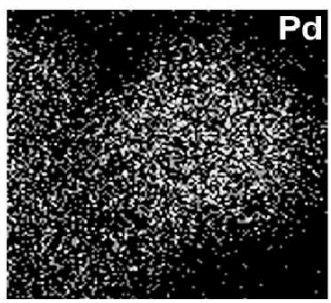

(b)

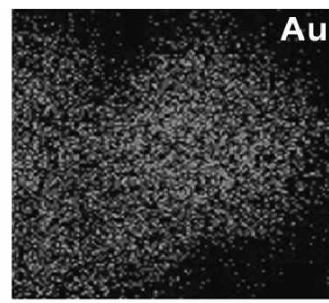

(d)

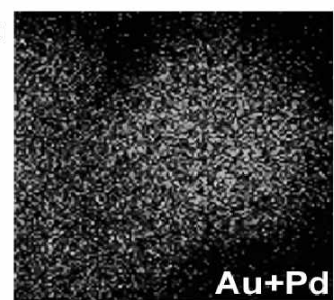

Figure 2. (a) High-magnilication STFM image of Au-Pd (1:1) bimetallic parlicle, (b-d) STFM-F.DS mapping images of (a): (b) Au mapping image. (c) Pd mapping image. and (d) overlapped image of (b) and (c).

\section{Results and Discussion}

When a piece of Ge wafer was soaked into the solution of I $\mathrm{AuCl}_{1} / \mathrm{Na}_{2} \mathrm{PdCl}_{1}$ misture, a thin lilm of $\mathrm{Au}-\mathrm{Pd}$ binctallic nanoerystals was readily fonmed on the Ge surface within $I$ hrr. As shown in Figure 1, the resulting lilms are composed of numerous nanocrystallites while their morphologies are sljghtly but obviously varied according to the ratios of Au to $\mathrm{Pd}$. As the eontent of a specitic component in the mixed preeursor solution is increased the morphology of the product resenbles that ol its pure component. For example, the Au-Pd lilms prepared from the II $\wedge \mathrm{UCl} \mathrm{l}_{4} / \mathrm{Na}_{2} \mathrm{PdCl}_{4}$ mixture solution having 3:1 molar ratio (Au-Pd (3:1) in Figure la) shows individual nanocrystals with an average diameter of approximately $174 \mathrm{~nm}$. which is similar to that of pure $\Lambda \mathrm{u}$ film of which average diameter is slightly lager (approximately $266 \mathrm{~mm}$, Figure 1d). Similarly, the $\Lambda$ u-Pd film prepared from the $\mathrm{I} \wedge \mathrm{uCl} \mathrm{L}_{4} / \mathrm{Na}$ $\mathrm{PdCl}_{1}$ mixture solution having $1: 3$ molar ratio (Au-Pd (1:3) in Figure lc) displays similar morphology to that of pure l'd film (Figure le) as satellite-type nanoer stal aggregations are found from both of them (for clarity, sec the larger sire STM images (Figure Sl) in Supplementary Electronic Material). Meanwhile. the mophology of Au-Pd alloy prepared from $\mathrm{Au}-\mathrm{Pd}(\mathrm{l}: 1)$ solution shows a unique morphology that is dissimilat to either pure Au or l'd (Figure lb). Note that the pure Au and l'd nanocrystal films were prepared by soaking Ge wafers into $1 \mathrm{mM}$ of $\mathrm{HAuCl}_{4}$ and $1 \mathrm{mM}$ of $\mathrm{Na}_{2} \mathrm{PdC} l_{1}$ aqueous solutions, respectively, at rom temperature for $12 \mathrm{hr}$.

To qualitatively confirm the formation of Au- $\mathrm{I}^{\mathrm{d}} \mathrm{d}$ bimetallic particles, we examined the chemical composition changes of the Au-l'd films by EDS attached to SEM. The results indicate that the mole fractions of $\mathrm{Pd}$ in $\wedge u-\mathrm{Pd}(3: 1), \wedge u-P d(1: 1)$. and Au-Pd ( $1: 3$ ) bimetallic films are $0.26,0.47$, and 0.77 , respectively (Figure If-h), which are closely consistent with the molar ratios in the feeding solutions. The distribution and homogeneity of each component in individual Au-l'd nanocrstyallites were further characterized by STFM-FTS analyses. According to the typical STEM image of a bimetallic $A u-P d$ (1:1) particle (Figure 2a) and EDS mapping data (Figure 2b-d), Au and l'd atoms are unifomly distributed over the entire particle without any predominance of specific component.

The formation of $\mathrm{Au}-\mathrm{Pd}$ alloys was further contimed by systematically investigating their XRD patterns with those of films composed ol $\triangle \mathrm{Au}$ and Pd individual nanocrystals (Figure 3 a-e). Each XRD pattem exhibils (wo major diflraction peaks in the range of $35^{\prime \prime}<2 \theta<50^{\circ}$, which are originated from ( 111 ) and (200) planes of the $f c c$ metallic $\Lambda u$ and Pd structures. In the case of pure $\Lambda$ unanorystal film, the $2 \theta$ values corresponding to the diliraetions from $\Lambda \mathrm{u}(111)$ and $\Lambda \mathrm{u}(200)$ are $38^{\circ}$ and $44^{\circ}$, respectively (Figure $3 a$ ). When Pd contents are gradually increased, these two peaks are systematically shifted to higher 20 values, and eventually getting closer to the 20 values of $40^{\circ}$ and $47^{\prime \prime}$ corresponding to $\mathrm{Pd}(111)$ and $\mathrm{Pd}(200)$ (Figure S2). To further comlinn whether such a systematic shilt is indecd distirnctive for the formation of $\mathrm{Au}-\mathrm{Pd}$ alloy rather than individual $\mathrm{Au}$ and Pd nanocrystals, we exam ined diliraction pattems with samples prepared (1) by secpuential treatment with $1.0 \mathrm{mM} \mathrm{HAuCl}\lrcorner$ followed by with $1.0 \mathrm{mM} \mathrm{Na} \mathrm{PdCl}_{4}$ 

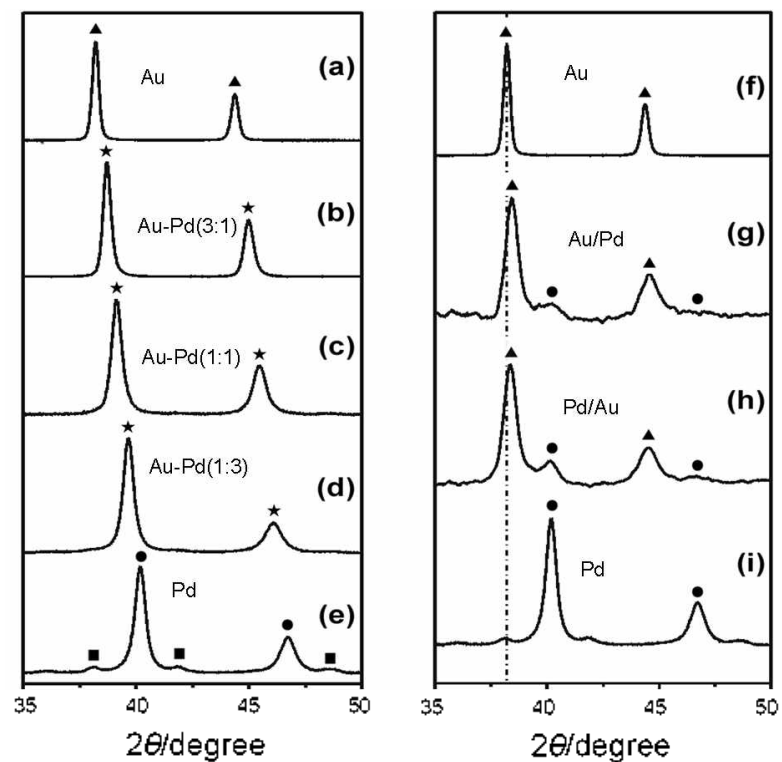

Figure 3. (a-e) $\mathrm{XRD}$ pattems of $\mathrm{Au}, \mathrm{Au}-\mathrm{Pd}$ and $\mathrm{Pd}$ nanocrystal films prepared on Ge substrates by the simultaneous galvanic displacement reaction from mixed aqueous solutions of $\mathrm{HAuCl}_{4} / \mathrm{Na}_{2}$ $\mathrm{PdCl}_{4}$. (f-i) XRD pattems of $\mathrm{All}, \mathrm{Au} / \mathrm{Pd}, \mathrm{Pd} / \mathrm{All}$, and $\mathrm{Pd}$ nanocrystal films. Note that $\mathrm{Aw} / \mathrm{Pd}$ and $\mathrm{Pd} / \mathrm{Au}$ were prepared by sequential galvanic displacement reactions. ( $\mathbf{\Delta}: \mathrm{Al}, \bullet: \mathrm{Pd}, \star$ : All-Pd, $\mathrm{GeO}_{2}$ ).

solutions on a Ge substrate (All/Pd. Figure 3g). and (2) by sequential treatment with $1.0 \mathrm{mM} \mathrm{Na} \mathrm{PdCl}_{4}$ followed by 1.0 $\mathrm{mM} \mathrm{HAlCl} \mathrm{l}_{4}$ solutions on a Ge substrate (Pd/Aul, Figure $\left.3 \mathrm{~h}\right) .{ }^{19}$ As shown in Figure $3 g$ and $h$ four peaks in total corresponding to the peaks from individual Au (triangles) and Pd (circles) are simultaneously observed without a noticeable shift. Note that the small peaks at $38^{\circ} .42^{\circ}$ and $49^{\circ}$ in Figure $3 e$ (squares) are originated from $\mathrm{GeO}_{2}$ (JCPDS No. 04-0497). ${ }^{\text {. }}$ The molar compositions of $\mathrm{Au}$ and $\mathrm{Pd}$ in the alloy thin films could be also estimated by the lattice parameter shifts calculated from the angular positions of the (111) diffractions according to Vegard's law. ${ }^{31}$ The mole fractions of Pd in Au- Pd (3:1), Aul-Pd (1:1). and All-Pd (1:3) alloy thin films were estimated to be 0.26 . 0.46 , and 0.74 . respectively. which agrees well with the aforementioned EDS results.

The successfully formed Aul-Pd alloy's would populate both Au and Pd on their surfaces. Such well-developed surfaces were evaluated by SERS measurements with 1.4-PDI as an adsorbate. It has been reported that isocyanides are readily

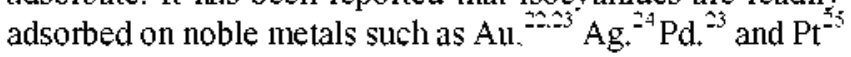
through the metal- $\mathrm{CN}$ bonds. of which bonding types are distinctively different depending on the kinds of metal substrates. For example. isocyanides adsorb on Au and Pd surfaces via pure $\sigma$ interaction and $\sigma / \pi$ synergistic interaction, respectively: Therefore. the scattering peaks at various energies due to different degrees of bonding characters can become a signature for the surface nature. The surface of Au-Pd alloys adsorbed with 1.4-PDI would exhibit scattering features originated from both Au and Pd developed on the Au-Pd alloy surfaces. Indeed. significant differences were observed in the SERS spectra upon the adsorption of 1.4-PDI on Au. Pd, and

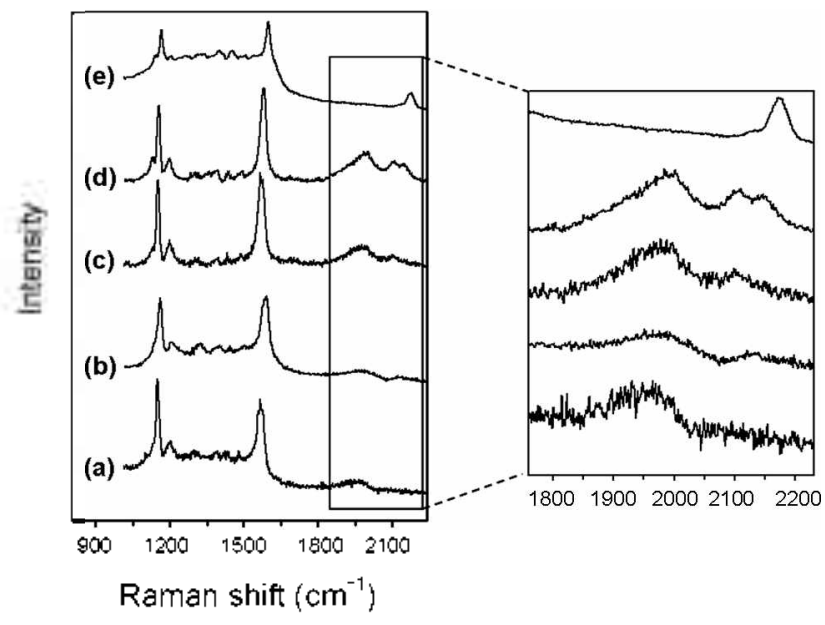

Figure 4. SERS spectra of 1,4-PDI on (a) Pd, (b) Au-Pd (1:3), (c) Au-Pd (1:1), (d) Au-Pd (3:1), and (e) Au films. All spectra were nomalized with 8 a mode peak at $1600 \mathrm{~cm}^{-1}$ for more easy comparison.

Au-Pd alloy films. While the characteristic NC stretching band appeared at $1965 \mathrm{~cm}^{-1}$ (strong and broad) and $2120 \mathrm{~cm}^{-1}$ (very weak) on pure Pd surface (Figure $4 \mathrm{a}$ ). the corresponding peak appeared at $2170 \mathrm{~cm}^{-1}$ in the case of pure Au surface (Figure +e). In contrast. the SERS spectra of 1.4-PDI on Au-Pd alloy films show peaks in two regions at around $1970 \mathrm{~cm}^{-1}$ and $2150 \mathrm{~cm}^{-1}$ which should be originated from $\mathrm{Pd}$ and Au. respectively (Figure $4 \mathrm{~b}-\mathrm{d}$ ). This result indicates that the surface of Au-Pd alloy is populated with both $\mathrm{Au}$ and $\mathrm{Pd}$. which is in a good agreement with the previous report. ${ }^{26}$ I.4-PDI molecules are supposed to adsorb on Au entirely at the on-top site, whereas both the on-top site and the 3-fold hollow site (open-faced trinuclear metal clusters) are occupied by 1,4-PDI molecules in the case of Pd surface. ${ }^{23}$ When 1.4-PDI molecules bind to Au-Pd alloy particles. instead of simple mixture of Au and Pd particles, the adsorption of 1,4-PDI molecule would be more complicated due to the co-presence of preferred binding sites of which populations are significantly varied according to the population of exposed Au and Pd on the surface of Au-Pd alloy particles. Such a conplicated adsorption phenomenon is an another indirect evidence for the successful formation of Au-Pd alloy particles. and indeed represented in the Raman spectra as a peak slift (red-shift toward lower frequency. Figure $4 b-d$ ) and peak split shown at near $2140 \mathrm{~cm}^{-1}$ (Figure 4d).

The co-deposition of two different metal ions into alloys has been widely studied for various applications. which is frequently quoted as an anomalous electrodeposition due to its lack of understanding about the mechanism. ${ }^{27-3(1)}$ Although the mechanism for the fonnation of Au-Pd alloy' by the spontaneous reduction of $\mathrm{AuCl}_{4}^{-}$and $\mathrm{PdCl}_{4}^{2-}$ ions by Ge is not clear yet, several feasible scenarios can be suggested. First. $\mathrm{AuCl}_{4}{ }_{4}$ ions are expected to be reduced first by Ge over $\mathrm{PdCl}_{4}{ }^{-}$even when they are co-present since the reduction of $\mathrm{AuCl}_{+}{ }^{-}$is thermodynamically much favorable considering their standard reduction potential values $\left(\mathrm{E}_{\mathrm{Au}}^{\mathrm{C}}{ }_{\mathrm{C}: \mathrm{l}} / \mathrm{Au}=+1.002 \mathrm{~V}\right.$ and $\mathrm{E}_{\mathrm{FHCl}}^{\circ}: \mathrm{Pil}=$ $+0.591 \mathrm{~V}$ is standard hydrogen electrode (SHE)) as shown in Figure $6 .{ }^{3]}$ Then, Au deposits would catalyze the further re- 
duction of $\mathrm{PdCl}_{4}{ }^{3-}$. 32 resulting in Au-Pd alloys. Meanwhile. the thermody namic advantage does not always necessarily decide the sequence of reduction of metal ions coexisting in a solution. For example. in $\mathrm{Zn}-\mathrm{Ni}$ alloys prepared by electrochemical co-deposition from a solution containing both $\mathrm{Ni}^{2-}$ and $\mathrm{Zn}_{\mathrm{n}}{ }^{\mathrm{i}}$ ions. $\mathrm{Zn}$ has been always richer than $\mathrm{Ni}$ in the products despite its thermody namic disadvantage $\left(\mathrm{E}^{\mathrm{O}} \mathrm{zn}^{-}: \mathrm{Z}_{\mathrm{n}}=-0.762 \mathrm{~V}\right.$ and $\mathrm{E}_{\mathrm{N}-\mathrm{N}}^{\circ}=-0.257 \mathrm{~V}$ is $\mathrm{SHE}$ ). ${ }^{33-35}$ For the similar sense. we cannot exclude another possible mechanism for the Au-Pd alloy's that involves the first reduction of $\mathrm{PdCl}_{4}{ }^{2-}$ ions followed by the Au-Pd alloy formation through the spontaneous charge transfer from $\mathrm{Pd}^{-1}$ to $\mathrm{AllCl}_{4}{ }^{-}$ions ( $\mathrm{E}^{\circ}$ for $\mathrm{Pd}+\mathrm{AllCl}_{4}{ }^{-} \rightleftharpoons$ $\mathrm{All}+\mathrm{PdCl}_{4}{ }^{\mathrm{i}-}$ is $+0.40 \mathrm{l}$ ).

\section{Conclusions}

The spontaneous formation of Au-Pd bimetallic films wia galvanic displacement at room temperature was successfully demonstrated. The composition ratio of $\mathrm{Au}$ and $\mathrm{Pd}$ of the alloys are controlled by simply controlling the mole fractions of Pd to $\mathrm{Au}$ in the precursor mixture solution. The formation of $\mathrm{Al}-$ $\mathrm{Pd}$ alloys rather than individual $\mathrm{Au}$ and $\mathrm{Pd}$ monometallic nanocrystals was confirmed by the sy stematic shifts of XRD peaks of (111) and (200) planes and by the SERS intensity originated from the chemical interactions of 1.4-PDI on All-Pd alloys. Since the Au-Pd alloys formed by the galvanic displacement are free from organic capping or structure directing molecules that may have played as a barrier for charge carrier mobility. they are expected to realize the perfonnance improvement in various applications including nanoelectronics. catalysis, fuel cell, hydrogen sensor, and other related fields.

Aclonowledgments. This study was supported by a grant of the Korea Healthcare technology R\&D Project. Ministry for Health, Welfare \& Fanily Affairs. Korea (A090062), and partly by the National Research Foundation of Korea (NRF) grant funded by MEST (2008-04306. 2007-8-1158, 2005-01325). KOSEF through EPB center (R11-2008-052-02000). H.C.C thanks the World Class University (WCU) program (R3 1-2008$000-10059-0$ ). We also thank Prof. Su-Moon Park at UNIST for fnuitful discussion.

Supporting Infomation. The SEM images of Figure Sla-e are available on request from the correspondence author.

\section{References}

1. Burda, C. Chen, X.; Narayanan, R.; El-Sayed M. A. Chem. Rev $2005,105,1025-1102$

2. Rosi, N. L.: Mirkin, C. A. Chem. Rev, 2005, 105, 1547-1562.

3. Ozin, G. A. Arsenult, A. C. Banochentistry: A Chemical Approach to Vamontaterials RSC Publishing: Cambridge, 2005

4. Cheon, J.: Lee, I.-H. Acc Chem Res. 2008, H, 1630-1640.

5. Dhar, S.: Reddr, E; Shiras, A.; Pokharkar, V; Prasad, B. Chem. Eur. J. 2008, If, 10244-10250.

6. Liu, H.: Chen, D.; Tang,, : Du, G., Li, L.: Meng, X.: Liang, W:;
Zhang, Y.: Teng, X.; Li, Y. Kanotecholog, 2008, 19, 455101

7. Hanck, T. S.: Jennings, T. L.: Yatsenko, T.; Kumaradsa, J. C.: Chan, W. C. W. Adr. Mater: 2008, 20, 3832-3838.

8. Porter, L. A.; Choi, H. C.; Buriak, J. M. Komo Lett. 2002, 2, 1067 1071

9. Porter, L. A.: Ribbe, A. E.; Buriak, J. M. Nano Left. 2003, 3 , $1043-1047$

10. Aizatła, M.; Cooper, A.; Malac, M; Buriak. T. M NanoLett. 2005, 5. 815-819

11. Aizawa, M.: Buriak, T. M. J. Am. Chem. Soc. 2005, 127, 89328933 .

12. Homozi Nezhad, M. R.; Aizawa, M.; Porter, L. A.; Ribbe, A. E.: Buriak. T. M. Small 2005, 1, 1076-1081.

13. Sayed, S. Y.: Daly, B.: Buriák, J. M. J. Phus Chem C 2008, 112. 12291-12298.

14. Toshima, N.: Yonezawa, T. New J. Chem 1998, 22, 1179-1201

15. Edwards, J. K; Hutchings, G. J. Angew. Chent htt Ed. 2008, $17,9192-9198$

16. Veneziá, A. M.: La Parola, V.: Deganello, G.: Pawelec, B.: Fierro, J. L. G. J. Catal. 2003, 215, 317-325.

17. Pawelec, B.; Cano-Serrano, E.; Campos-Martin, T. M.; Navaro, R. M. Thomas, S.; Fierro, J. L. G. Appl Catal. A 2004, 275, $127-139$

18. Enache, D. I.; Edwards, . . K.: Landon, P.: Solsona-Espriu, B.; Carley, A. F.; Herzing, A. A.; Watanabe, M.; Kiely, C. T.; Knight, D. W.; Hutchings, G. T. Science 2006, 311, 362-365.

19. $1.0 \mathrm{~mL}$ of aqueous solutions of $1.0 \mathrm{mM} \mathrm{HAuCl}$ and $1.0 \mathrm{mM}$ $\mathrm{Na}_{2} \mathrm{PdCl}_{4}$, were prepared. A piece of $\mathrm{Ge}$ water was immersed into the aqueous solution of $1.0 \mathrm{mM} \mathrm{HAuCl}$. After $15 \mathrm{~min}$, the gemanium wafer was rinsed with deionized water, and immersed again into the aqueous solution of $1.0 \mathrm{mM} \mathrm{Na} 2 \mathrm{PdCl}_{4}$ for another $15 \mathrm{~min}(\mathrm{Au} / \mathrm{Pd})$. The resulting Ge substrate was thoronghly rinsed with deionized water to remove unreacted precursors. and then dried under ambient conditions. The opposite sequential reaction was applied to prepare $\mathrm{Pd} / \mathrm{Au}$ sample.

20. Kim, H. W.; Shim, S. H.; Lee, I. W. Appl. Sm. Sci. 2007, 243, 72077210

21. Damle, C.; Kumar, A.; Sastry, M. J. Phvs. Chem. B 2002, 106 , 297-302.

22. Kim. N. H.; Kim, K. J. Phys. Chem. B 2006, 110, 1837-1842.

23. Swanson, S. A.: Mcclain, R.: Lovejoy, K. S.; Alamdari, N. B:; Hamilton, J. S.: Scott, J. C. Langmin 2005, 21, 5034-5039.

24. Han, H. S.; Han1, S. W. Too, S. W : Kim, K. Langmuir 1999, 15, $6868-6874$

25. Garrell, R. L. Anal Chem 1989, 61, 401A-411A.

26. Lee, Y. W.; Kim, N. H.; Lee, K. Y.: Kwon, K : Kim, M:; Han, S. W. J. Phys. Chem. C 2008, 112,6717-6722.

27. Chang, B.-Y. Park, S. M. J. Electrochent. Soc. 2004, 151, C786C788.

28. Hovestad, A.; Janssen, L. I. J. J. App. Elechochem. 1995, 25, $519-527$.

29. Chi, Q. J.; Dong, S. J. Anal. Chm. Acta 1995, 310, 429-436

30. Zech, N.: Podlaha, E. J.; Landolt, D. J. Electrochem. Soc. 1999. $1+6.2886-2891$

31. CRC Handbook of Chemisty and Physics, 84th ed.: Lide, D. R., Ed.: CRC Press: Boca Raton, FL, 2004.

32. Nutt, M. O.; Heck, K. N.; Alvarez, P.; Wong, M. S. Applied Catahsis B: Envirommental 2006, 69, 115-125.

33. Miranda, F. J. F.: Barcia, O. E.: Mattos, O. R.: Wiart, R. J. Electrochem. Soc. 1997, 144, 3441-3449.

34. Nichol, M. J.; Philip, H. L. J. Electromal. Chemt 1976, 70, 233-237.

35. Chassaing, E.; Wiart, R. Electrochim. Acta 1992, 37, 545-553 